\title{
REGRAS DE JOGO VERSUS REGRAS MORAIS \\ Para uma teoria sociológica do fair play
}

\section{Simone Magalhães Brito Jorge Ventura de Morais Túlio Velho Barreto}

\section{Introdução}

O que significa ter fair play? A ideia de fair play está ligada à noção de moralidade. $\mathrm{O}$ uso que os atores sociais fazem do termo, dentro de um jogo e até mesmo fora dele, remete a uma série de noções que, apesar de não estarem explicitamente presentes nas regras, são compreendidas por aqueles que compartilham de uma espécie de "boa vontade" ou, em outros termos, do "espírito esportivo". Um jogo em que o fair play é quebrado é definido por jogadores como um "antijogo". De acordo com o código de ética da Fifa, ${ }^{1}$ o fair play seria a regra de

* Uma versão preliminar deste trabalho foi apresentada no 33 Encontro Anual da Anpocs, 2009, no GT 27: "Para onde vai a Teoria Social contemporânea?". ouro ou o primeiro mandamento do futebol, sua ausência retiraria o brilho da vitória e quebraria o espírito de fraternidade que une os que vivem e admiram o futebol. Neste código enfatiza-se, como representação do fair play, o respeito pelas regras.

Também seria possível definir fair play como um conjunto de virtudes que, para além das regras, seriam capazes de resolver as ambiguidades encontradas nas situações de jogo. Ou seja, a ideia de "jogo limpo" representaria mais que uma regra, fornecendo aos atores parâmetros para julgar o que as regras não podem prever. Essa ideia de "uma regra para além das regras" torna-se ainda mais importante se pensarmos que a prática de diferentes esportes preenche uma demanda ou conjunto de virtudes com atos muito distintos. Por exemplo, esportes como boxe, rúgbi e futebol são muito diferentes em termos de suas regras de contato corporal; no entanto, apesar dessas diferenças, todos podem fazer uso da noção de fair play para resolver 
problemas surgidos em situações onde a regra não está clara.

Como hipótese inicial, podemos então entender que essa noção tornaria o jogo mais justo ao quebrar a tirania das regras ou corrigir as falhas de sua aplicação. Assim, o fair play poderia ser interpretado como um "respeito pelo jogo", evitando a sua instrumentalização (ganhar como único objetivo) e garantindo a prática do esporte como um fim em si mesmo.

Contudo, uma importante vertente da sociologia dos esportes oferece importantes argumentos para confrontar essa perspectiva filosófica do fair play. A sociologia figuracional de Norbert Elias, em especial a partir de sua colaboração com Eric Dunning, afirmam que a busca por um jogo limpo nasceu na Inglaterra principalmente em virtude de uma necessidade dos apostadores. A preocupação com as regras e sua justiça está na origem dos esportes modernos e, especialmente, ligada a uma necessidade daqueles que vão "investir" no jogo e que, portanto, precisam de garantias de que as condiçôes iniciais não os prejudicariam (Elias e Dunning, 1995).

O objetivo deste trabalho é mostrar que a oposição entre as interpretações do fair play está diretamente ligada a questôes fundamentais para a teoria sociológica. Existe um valor buscado e respeitado pelos jogadores e, mais importante, esse valor é vivido como o oposto da instrumentalização: é o momento em que a prática esportiva se aproxima de uma vida correta e virtuosa. Para um sportsmen, cometer uma falta é normal, mas não jogar limpo é muito grave. Um jogador que comete muitas faltas pode ser considerado violento, mas, em certos momentos, essa característica pode até vir a ser apreciada pela comunidade dos jogadores. Contudo, a acusação de falta de fair play exclui e estigmatiza de forma definitiva. Como a perspectiva sociológica pode lidar com essa justificativa de que o fair play é mais do que uma simples regra e de que quebrá-la é pior do que quebrar outras regras? É possível a afirmar que as regras morais são de natureza distinta das regras sociais?

De acordo com a perspectiva de problematização dos valores morais na sociologia, talvez a questão mais importante seja a da universalidade do fair play. Por que esportes tão diferentes, com regras tão distintas, possuem a noção de fair play? Situações e disposiçóes tão diversas quanto aquelas presentes no badminton e no boxe admitem o recurso ao mesmo princípio. Ainda, situações oficiais (com juízes, organização etc.) e situações de "brincadeira" também requerem a mesma virtude. Como é possível dar uma explicação sociológica para esta constatação?

Estamos diante de uma questão muito simples: por que os atores, em situações tão diversas, recorrem ao fair play? Ou, por que não existem jogos (ou pelo menos festivais) que decidam aboli-lo? O fato de a abolição do fair play causar repulsa ou riso é resultado de um processo civilizador ou de um valor moral transcendente? Caso o fair play seja um requerimento típico de uma figuração inglesa, como se explica que ele tenha se adaptado a tantas culturas distintas?

A simplicidade do uso do fair play pelos atores sociais contrasta com a dificuldade de apresentar a sua explicação. Assim, a ideia deste trabalho é demonstrar como essa dificuldade revela a falta de uma perspectiva sociológica adequada à especificidade do fenômeno moral. $\mathrm{Na}$ discussão que se segue pretendemos elaborar uma definição do fair play por meio do confronto entre sua explicação filosófica e sociológica e, com isso, apresentar alguns dilemas que vêm à tona quando se busca uma compreensão sociológica da moralidade.

\section{Fair play e regras do jogo}

O entendimento do fair play requer, inicialmente, uma discussão sobre regras de jogo. Quer sua natureza seja instrumental (a garantia da possibilidade de investimento seguro) ou transcendental (o respeito pelo jogo), o fair play mantém sempre uma relação reflexiva com as regras e os fundamentos do esporte em questão. Antes de passarmos para uma abordagem filosófica e sociológica do fair play é importante realizar uma caracterização baseada em um caso paradigmático com o intuito de definir mais claramente o objeto em foco. Tomando, no caso específico do futebol, um exemplo de relação com as regras podemos apresentar os usos práticos da ideia de fair play. 
Para ter fair play é necessário seguir as regras, contudo, quebrá-las não significa, necessariamente, sua ausência. Faz parte do entendimento do futebol perceber a inevitabilidade de certas faltas e até mesmo sua necessidade em algumas situaçôes. Entender que tipo de quebra da regra caracteriza falta de fair play está relacionado com a intencionalidade do ato, o que, obviamente, gera conflitos de interpretação. Mas, podemos citar o gol feito com a mão como um exemplo sobre o qual se constrói o acordo. A polêmica tão famosa na história do futebol brasileiro mão na bola x bola na mão é um exemplo claro. A primeira é necessariamente a representação a ausência de fair play. É impossível pensar um único caso em que um gol de mão seria considerado justo no futebol. Assim, no gol de Maradona na Copa do México de 1986, que ficou conhecido como "La mano de Dios", apesar de toda a discussão moral que pode suscitar, houve ausência de fair play. Contudo, a segunda situação ("bola na mão") não significa falta de fair play; a quebra do espírito ocorrerá num momento posterior se não houver a admissão do ato.

É muito claro que não pode existir fair play sem respeito pelas regras. No caso particular da Fifa, existe uma tentativa de institucionalização do fair play que está presente no incentivo ao cumprimento das regras e no respeito pelas decisōes do juiz. ${ }^{2}$ Contudo, é fundamental para o argumento aqui apresentado entender em que medida o senti-

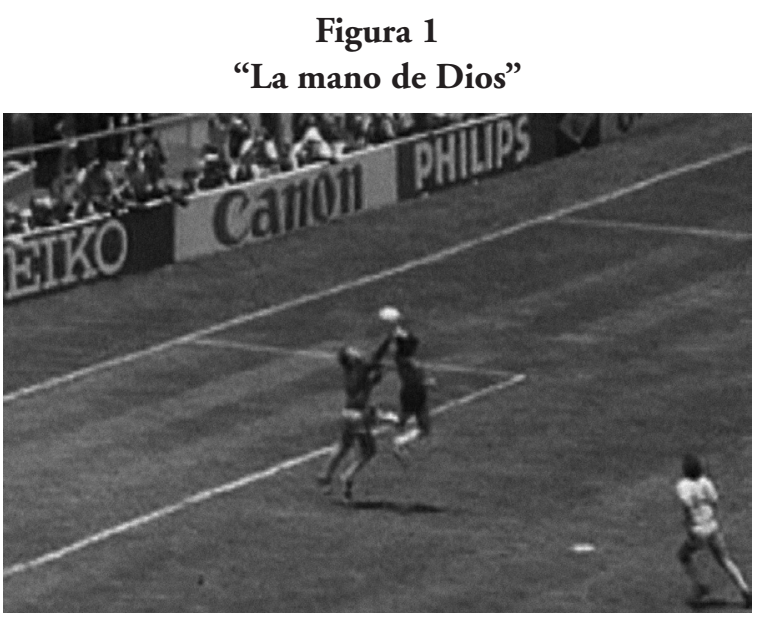

Fonte: DVD Maradona, A vida de um gênio do futebol. São Paulo, Editora Abril, s/d (col. Grandes Craques). do do fair play é mais amplo do que as regras e sua legalidade. Para isso, partiremos de um exemplo do futebol que representa um caso paradigmático, em que, a partir de uma explicação da regra e suas nuanças, percebe-se como, mesmo agindo dentro da regra, também pode haver violação da noção de jogo limpo.

As regras do futebol dão sentido, estruturam táticas e estratégias, e conferem identidade a este e todos os outros esportes. Sem elas, não teríamos o futebol tal como o conhecemos hoje. As regras, no entanto, não estruturam o futebol de modo "fechado". Com efeito, ao mesmo tempo em que influenciam fortemente sua dinâmica, as regras são utilizadas criativamente pelos jogadores de ambos os times para ultrapassar obstáculos e alcançar a meta adversária.

Consideremos dois times dispostos em campo. Um está atacando e o outro, obviamente, se defendendo. O time em posição de defesa dispõe-se em campo de acordo com as disposiçôes táticas do seu treinador (e a criatividade dos jogadores), que se baseia, entre outros fatores, na existência de certas regras, a exemplo da regra do impedimento.

O time em posição de ataque, por sua vez, tem de considerar uma série de dificuldades a serem vencidas se quiser chegar ao gol adversário, entre elas a existência da Regra 11 - a do impedimento -, que limita o número de jogadas permitidas.

Vejamos o que dispóe esta regra, de acordo com a Fifa:

\section{Regra 11 - O Impedimento}

Posição de impedimento

O fato de estar em uma posição de impedimento não constitui uma infração.

Um jogador estará em posição de impedimento quando:

- se encontrar mais próximo da linha de meta adversária do que a bola e o penúltimo adversário.

Um jogador não estará em posição de impedimento quando:

- se encontrar em sua própria metade de campo, ou

- estiver na mesma linha do penúltimo adversário, ou 
- estiver na mesma linha dos dois últimos adversários

Infração

Um impedimento somente será marcado se, no momento em que a bola for tocada ou jogada por um de seus companheiros, o jogador estiver, na opinião do árbitro, envolvido em jogo ativo:

- interferindo no jogo, ou

- interferindo num adversário, ou

- ganhando vantagem por estar naquela posição Não há infração

Não haverá impedimento se um jogador receber a bola diretamente de:

- um tiro de meta, ou

- um arremesso lateral, ou

- um tiro de canto

Infraçōes e Punições

Por qualquer impedimento, o árbitro deverá conceder tiro livre indireto para a equipe adversária, que será executado no local onde ocorreu a infração [...]..$^{3}$

Portanto, o time em posição de ataque não pode marcar um gol a partir de qualquer posição. Há restriçōes. Um atacante não pode ficar simplesmente em frente ao goleiro esperando a bola chegar para marcar um gol, o que caracterizaria o impedimento.

Mas vejamos as exceçôes, as brechas, que permitem a criatividade, a manipulação e a estrategização por parte dos jogadores. Primeiro, a regra é enunciada de forma negativada, isto é, estar em posição de impedimento não constitui em si mesmo uma infração. Em outras palavras, se um jogador estiver em posição de impedimento, mas não participar da jogada ("interferindo no jogo, ou interferindo num adversário, ou ganhando vantagem por estar naquela posição”), o árbitro não deverá sancionar a infração.

No entanto, quando estas ressalvas foram introduzidas como "decisão infraconstitucional", ${ }_{4}^{4} \mathrm{em}$ 2003 - e de forma mais clara em 2005 -, alguns times começaram a utilizar o novo entendimento da regra como uma estratégia de ataque para burlar as defesas adversárias. Se estar em impedimento sem participação na jogada não constitui em si uma infração, então alguns técnicos começaram a divisar a estratégia de colocar atacantes em posição de impedimento, mas sem participação na jogada, com o intuito único de confundir os defensores.

$\mathrm{Na}$ Inglaterra, há notícias de que alguns times das divisões inferiores começaram a usar esta tática, porém ela só chamou a atenção da imprensa em 2004, quando Sam Allardyce, então técnico do Bolton Wanderers, a pôs em prática:

Em um jogo contra o Leicester City [da Inglaterra], particularmente com relação ao impedimento passivo e ativo, [Allardyce] colocou dois jogadores em posição de impedimento em tiros livres. Os jogadores corriam de volta tão logo a falta era cobrada. Na primeira vez, Kevin Nolan, um dos jogadores 'em impedimento' chutou na trave e na segunda marcou um gol. Foi uma jogada maravilhosamente coreografada e, pelo menos no que diz respeito a Allardyce, uma resposta perfeita a uma regra que, na opinião dele, estava colocando o valor de entretenimento do jogo em perigo. ${ }^{5}$

Antes deste evento, jogadores tais como Ruud van Nistelrooy, então no Manchester United, e Thierry Henry, então no Arsenal, ambos da Inglaterra, já haviam desenvolvido estratégias individuais para se beneficiar da nova interpretação da regra. Eles costumavam se colocar em posição de impedimento, de modo a confundir as defesas, e, à medida que o jogo evoluía em direção a eles, se colocavam em posição legal novamente (onside em oposição a offside, na expressão inglesa).

Allardyce parece ter sido o primeiro técnico a pensar em usar a nova interpretação de forma deliberada como tática coletiva de jogo. Na Figura 2, percebemos graficamente a utilização estratégica que Allardyce fez da nova interpretação da Regra 11. Qual é a implicação da estratégia? Enquanto um jogador do Bolton se prepara para cobrar uma falta, dois dos seus companheiros se postaram lá na frente em posição de impedimento.

As setas indicam a movimentação dos jogadores do Bolton para fora da jogada com o intuito de indicar ao árbitro que não estavam participando da jogada. Ou seja, uma utilização da brecha legal permitida pela nova interpretação da Regra 11. 
Figura 2

“O Bolton Colocou Deliberadamente Jogadores (de Camisas Brancas) em Posição de Impedimento"

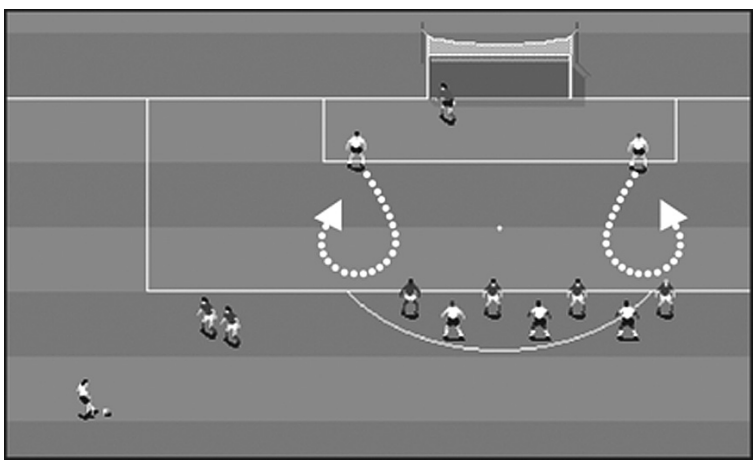

Fonte: Disponível em <http://news.bbc.co.uk/sport1/hi/football/3479755.stm>, acessado em 20/10/2008.

No entanto, esta utilização da regra do impedimento encontrou, no início, uma reação mista. John May, ${ }^{6}$ comentarista do site da BBC Sports afirmou que a jogada faz parte do jogo e que é o trabalho de cada técnico encontrar uma pequena brecha que o permita vencer o jogo. Porém, em uma aparente contradição, Sam Allardyce condenou sua própria tática ao afirmar que:

Eu acho que a Fifa errou. Não há nada que eu possa fazer, a não ser usá-la [a nova interpretação] em nosso favor, mas eu não gosto dela. Ela [a nova interpretação] não adiciona nada ao jogo, a não ser confusão. Mais cedo ou mais tarde, nós vamos ter os 22 jogadores dentro da pequena área na hora de um tiro livre (The Independent on Sunday, 15.2.2004).

A controvérsia também foi grande, principalmente entre os técnicos que se sentiram lesados com a nova tática.

Como resultado de toda esta reação à estratégia de Allardyce, a Football Association (Federação Inglesa de Futebol) decidiu recomendar, depois desse lance, que tal conduta fosse punida com cartão amarelo por se caracterizar, de acordo com a noção de fair play, uma conduta antidesportiva. Porém, o mesmo não se pode dizer de partidas disputadas fora da Inglaterra. Vale lembrar que Sam Allardyce se desculpou posteriormente por ter usado esse expediente. $^{7}$ Ou seja, apesar de ser legalmente permitida, a jogada analisada parece violar o sentido pelo menos na Inglaterra - de fair play - isto é, o sentido do que é considerado legítimo, esperado dos contendores com base no entendimento compartilhado do que é legítimo.

$\mathrm{Na}$ verdade, o sentido do fair play está numa atitude que vai além do que pede a regra e, especialmente, fere o interesse exclusivo de ganhar. Vejamos alguns exemplos:

1. Num jogo do campeonato holandês, ${ }^{8}$ o Ajax teve um jogador machucado num lance comum do futebol. Para seguir o uso do fair play, os adversários do Cambuur Leeuwarden tocaram a bola para fora. ${ }^{9}$ Quando o jogo é reiniciado, Jan Vertonghen do Ajax devolve a bola ao goleiro adversário, mas, sem intenção, marca um gol. Apesar do constrangimento, este gol foi validado pelo árbitro, pois o ato não feria as regras. Após alguma discussão e constrangimento por parte de alguns jogadores, foi decidido que o Ajax não fizesse nada para impedir a saída e o consequente gol do Cambuur. A imagem dos jogadores imóveis diante do gol tem o verdadeiro sentido ético e estético do espírito esportivo contido no fair play.

2. Na Inglaterra, em 1999, Ray Parlour, então do Arsenal, tentou devolver uma bola a um jogador do Sheffield United. No entanto, o atacante Nwuankwo Kanu, que tinha acabado de entrar e não percebeu o ato de fair play, desconsiderou essa intenção e interceptou o passe, tocando para Marc Overmars que fez o gol diante dos adversários parados. Com esse gol, o Arsenal venceu por 2 a 1 . No entanto, o técnico Arsene Wenger decidiu oferecer aos oponentes a possibilidade de jogar a partida novamente. Mais uma vez, apesar de não haver nenhum descumprimento da regra que justificasse nova realização do jogo, a Fifa autorizou uma nova partida em nome do fair play.

Esses dois exemplos demonstram que o fair play contém um sentido diferente da necessidade contida na regra; trata-se de uma ação que requer 
dos indivíduos uma interpretação do jogo capaz de suspender momentaneamente sua finalidade de ganhar e os interesses individuais. É preciso acrescentar que o fair play não está sendo aqui ingenuamente entendido como uma experiência mística que arrebata os atores sociais envolvidos na situação e os separa das preocupações instrumentais. Pelo contrário, nos dois exemplos apresentados, e quantos outros se queira, existe uma discussão e disputa entre os envolvidos até o que o sentido de fair play seja escolhido e se estabeleça. Essa escolha, para se estabelecer, precisa sempre se defrontar com opções como a de Edmundo, na Copa de 1998, que, diante do fair play de Rivaldo, ao colocar a bola para fora para que o adversário francês recebesse atendimento médico, grita revoltado: "Isso é aqui é final de Copa do Mundo!". ${ }^{10}$

\section{Filosofia do fair play}

Nos casos apresentados temos três exemplos de dilemas desenvolvidos durante a aplicação das regras do jogo. Apesar de suas diferenças, todos foram resolvidos com base no mesmo tipo de referência a valores. Assim, estamos diante de uma regra que regula a aplicação de outras regras, um valor que é usado para corrigir algumas possibilidades legais do jogo. Alguém poderia argumentar que esta ideia não se aplica aos dois últimos casos, afinal o fair play foi usado para reparar a sua própria quebra. Contudo, o mesmo não pode ser dito do primeiro exemplo: nele temos uma situação em que um uso válido da regra de impedimento foi julgado inapropriado com base em um sentido que não está presente nas regras do jogo. Que sentido é esse? Como é possível que o mesmo sentido ou ideia seja aplicado a uma variedade de situaçóes diferentes? Fora do âmbito futebolístico, como é possível que práticas tão distintas em termos de suas regras, como boxe, rúgbi, badminton e cricket, apenas para dar alguns exemplos, possam também fazer uso da mesma referência ou do mesmo valor regulador?

Pelo fato da ideia de fair play conjugar uma série de valores que pretendem determinar o que é bom e correto não apenas nas situações de jogo, mas também na vida, podemos afirmar que se tra- ta de um debate moral. Contudo, apesar da clara identificação do fair play com o terreno da ética e da moral, não há um consenso na filosofia dos esportes sobre o que é fair play, levando a uma variação de perspectivas concorrentes (Sheridan, 2003, p. 163). Sheridan classificou seis interpretaçōes filosóficas do fair play que passamos a descrever agora:

1. Fair play como formalismo: esta perspectiva considera que o fundamento de validade de todas as açôes num jogo é o corpo de regras que rege o esporte específico. Assim, a consideração de fair play deve-se ao cumprimento das regras próprias de cada esporte (Idem, p. 165) $\mathrm{e}$, por conseguinte, inerente a qualquer prática esportiva.

2. Fair play como ludicidade: para essa concepção, a experiência dos jogos se daria num fluxo de vida que se opõe ao cotidiano, especialmente considerando a dimensão reificadora deste. Seria da natureza do jogo o prazer, o respeito pelo outro e a alegria. O problema desta explicação do esporte como uma atividade com um fim em si mesmo está quando pensamos nos esportes de alto rendimento, em que a ação dos atletas está orientada para a vitória e nas várias formas de trapaça (Idem, pp. 167-169).

3. Fair play como respeito pelo jogo: de acordo com esta perspectiva, o fair play exigiria muito mais do que respeitar as regras do jogo, seria a adoção de uma postura particular diante das regras do jogo. Essa postura pode incluir o respeito pelo outro, o autorrespeito, o respeito pelo espírito do jogo (como no exemplo do Código de fair play da Fifa) ou o respeito pelo jogo (situação específica) (Idem, pp. 169-170). A adoção do fair play seria, então, mais que uma convenção social: seria um engajamento na prática esportiva, onde mais que seu próprio interesse, os jogadores estariam visando o interesse do jogo e adotando o ethos do jogo como seu próprio interesse.

4. Fair play como contrato: desde que os esportes são práticas cooperativas, cada jogador ao iniciar uma prática desportiva estaria concordando com um conjunto de regras; seria um contrato tácito. Assim, ter fair play significaria 
uma aceitação da forma de competição estabelecida e a promessa de cumprimento do contrato implicitamente acordado no início do jogo (Idem, pp. 170-172).

5. Fair play como um sistema de normas racionais: todos os esportes compartilhariam um núcleo ético, uma espécie de consenso mínimo sobre a necessidade de justiça e imparcialidade. De acordo com este código de ética, ao qual o fair play faria referência, violaçōes intencionais da norma não fazem parte do ethos de nenhum esporte.

6. Fair play como virtude: neste caso, o fair play estaria ligado ao (bom) caráter dos jogadores. Mais do que por obediência e medo das penalidades, a observância das regras pelos membros virtuosos da comunidade de jogadores se daria pela sua relação particular de respeito ao esporte. Contudo, esse bom caráter não deriva da estrita observância das regras, mas dos exemplos, dos modelos de boas ações que condensam princípios éticos que também são necessários fora das situaçōes de jogo. Para Lumpkin (apud idem, p. 175), as quatro virtudes que compõem o fair play são: justiça, honestidade, responsabilidade e benevolência.

Cada uma dessas perspectivas é importante para revelar o que é o fair play, contudo muitos problemas emergem quando da aplicação de cada uma para o entendimento de sua diversidade. Com o intuito de compreender melhor as consequências da adoção de cada uma dessas perspectivas, propomos uma divisão dessas abordagens em duas categorias: normativas e valorativas.

São abordagens normativas do fair play: o formalismo (1), a teoria do contrato (4) e o sistema de normas racionais (5). O que essas abordagens têm em comum é caracterizar o fair play como uma estrita observância de um conjunto de regras, sejam estas preestabelecidas ( 1 e 5 ) ou mesmo recentemente acordadas (4). O fundamento de uma prática desportiva, o que a distingue de outras figuraçōes, é o seu conjunto único de regras, e o fair play seria o compromisso com a manutenção deste fundamento. Tal abordagem apresenta o sentido mais geral e mais utilizado do fair play, contudo, possui proble- mas, uma vez que falar de uma estrita observância das regras não explicaria a diversidade de ações que acontecem nas práticas esportivas. Ainda, podemos apontar como problemáticos os seguintes aspectos: (a) o formalismo não considera que os jogos são formados por uma constante interpretação das regras e que, portanto, (b) há muitas açōes que não estão contidas nas regras do jogo e que só podem ser julgadas dentro de um contexto social específico (Idem, p. 165); e que (c) antes da aplicação das regras é necessário haver uma compreensão compartilhada entre os jogadores (e os juízes) de como as regras devem ser interpretadas (Idem, p. 167).

A solução da perspectiva normativa para as críticas que lhe são colocadas por sua falta de substância ou de referência à cultura particular de cada esporte é, por exemplo, considerar a existência de um ethos do jogo que determina como as regras são aplicadas em cada situação (D'Agostino, 1981). Contudo, consideramos que o problema permanece, pois a referência a um ethos específico de cada jogo apenas foge do problema sem lidar com a questão central que é a universalidade do fair play e sua aplicabilidade em situações específicas. Sejam regras de jogo gerais ou regras de um esporte específico, a dificuldade é saber como todos eles tentam resolver seus problemas fazendo uso da mesma modalidade de regra e, especialmente, do mesmo sentido. O racionalismo que é evidente na forma do contrato apresenta um quadro do processo de estabelecimento das normas, mas não é capaz de informar por que os contratos de jogo se referem sempre ao mesmo corpo de sentidos. Por que, por exemplo, não é experiência mais comum um contrato que preestabeleça a ausência temporária de fair play? Por que soa tão bizarro perguntar pela existência de um jogo que se joga suspendendo o fair play, um verdadeiro "vale-tudo"?11

A abordagem normativa informa sobre o estabelecimento ou os procedimentos empregados para a validade de um recurso ao fair play. Contudo, mesmo se pensamos no ethos de cada jogo, essa abordagem encontra problemas para explicar tanto o significado, como a universalidade do fair play. Se esta estivesse na sua relação com as regras, recorrer a ele como padrão de julgamento, seria desnecessário: bastaria que se apelasse à regra pura e simples. 
As abordagens valorativas do fair play estão presentes nas noções de ludicidade (2), respeito pelo jogo (3) e virtude (6). Como o próprio termo afirma, essas abordagens dão ao fair play um valor em si ou um conteúdo. Pode-se dizer que estariam afirmando o espirito do jogo como algo que se dá para além do cumprimento de regras. Este seria tão somente uma condição de existência do jogo que não requer ou inclui o tipo de sentido a que se faz referência quando se recorre à ideia de fair play.

O que há em comum entre essas três concepções é a afirmação de um sentido que está para além da convenção estabelecida pelo jogo específico. O fair play requer o respeito às regras, mas, essa afirmação não acrescenta nada ao seu entendimento, pois seguir as regras é a condição para que haja jogo. Assim, o fair play seria um qualificativo da experiência do jogo ou uma "postura particular” diante das regras do jogo. Não existe necessidade, a adoção de fair play seria fruto da liberdade que a situação de jogo concede aos seus participantes. Por que escolher o caminho da justiça, honestidade, responsabilidade ou benevolência? Para essa perspectiva, não existe nenhum conjunto de regras de nenhum jogo em particular capaz de incorporar essas qualidades como normas, além do que sua expressão nem poderia ser definida de antemão sem ser esvaziada. Ademais, o próprio jogo seria um momento de suspensão da ordem vigente, de inversão da contingência que recai sobre os atores no cotidiano, trazendo, por isso, a possibilidade de experienciar alegria, respeito e proximidade do outro. De acordo com essa percepção, o fundamento do jogo não é ganhar, mas realizar a experiência de suspensão da vida ordinária e estabelecer um encontro com o outro sobre bases não instrumentais.

A principal crítica que se faz ao modo valorativo de conceber o fair play toma como base a realidade das competiçôes esportivas de alta performance. Em competições internacionais e entre atletas de maior rendimento ocorreria exatamente o oposto daquela experiência. $\mathrm{O}$ principal objetivo destes modos de jogar seria a vitória e todas as suas implicações para um mercado que movimenta altas somas. Como exemplo desta realidade basta citar o problema do doping.
No entanto, para as abordagens valorativas, estes casos, ao invés de contradizer, confirmam sua particular percepção do valor contido no fair play. O domínio do mundo dos esportes pela lógica instrumental estaria subvertendo os jogos a uma forma e imperativos únicos, reificando-os. A recorrência sistemática a formas destituídas de virtudes confirma uma transformação que o campo dos esportes impõe à experiência, e não algo que seja da natureza do jogo. Como exemplo desta universalidade da experiência do respeito e das virtudes encontra-se o caso dos esportes para os gregos, cuja finalidade consistia na honra de lutar, de tal modo que Heitor era tão valoroso quanto Aquiles.

\section{Sociologia do fair play}

Tanto as abordagens normativas como as valorativas consideram o fair play um valor moral que se dá em todas as situações de jogo, portanto, uma forma universal. Seria possível afirmar que estamos diante de um valor moral trans-histórico?

A perspectiva sociológica leva-nos para uma abordagem bem diferente de uma resposta positiva para esta questão. Tomando especificamente a sociologia figuracional de Norbert Elias (que além de uma importante abordagem dos esportes, também apresenta uma história do fair play), é possível apresentar uma análise sociológica da busca por um "jogo limpo" no mundo dos esportes que demonstrará como este valor está situado numa época específica e, na verdade, seria função de um ordenamento social mais amplo. Seguindo essa perspectiva, os exemplos apresentados seriam resultado de um desenvolvimento histórico particular, formado por processos de socialização e coerção.

Em primeiro lugar, é importante perceber que Elias, juntamente com Dunning, em sua análise dos esportes, estabelece uma distinção muito clara entre os valores ligados a práticas esportivas entre os gregos da Antiguidade e nosso sentido contemporâneo de fair play. Contrariando a perspectiva filosófica do "espírito da regra" como uma virtude universal, os referidos autores demonstraram como diferiam as práticas antigas e aquilo que se articulou a partir do século XVIII na Inglaterra. Para entender essa 
diferenciação é necessário, antes de tudo, fazer referência ao processo civilizador e como os esportes se situam em meio a esse processo histórico.

A caracterização do desenvolvimento do processo civilizador tem como aspecto-chave uma mudança da "sensibilidade" dos indivíduos. Essa transformação nos sentimentos e na conduta é "muito específica nos sentimentos de vergonha e delicadeza" (Elias, 1994a, p. 14). A expressão dos sentimentos na relação com os outros passou a ser objeto fundamental do controle social, não de maneira difusa ou dúbia, mas como um conjunto de regras específicas: "A regulação da conduta e dos sentimentos tornou-se mais estrita, mais diferenciada e englobadora, contudo, também mais equilibrada e moderada ao eliminar o excesso de autopunição" (Elias e Dunning, 1995, p. 37).

As regras de etiqueta são uma dimensão da vida social privilegiada para a percepção desta transformação histórica em curso. Seu alcance sociológico é amplo, pois implica uma transformação geral na relação com o corpo, especialmente com o corpo do outro e com os aspectos deste que devem tomar parte na vida social. As regras de controle de sons e fluidos corporais juntamente com regras de comportamento e comunicação estabelecem não apenas um conjunto de normas mundanas e superficiais, mas também são internalizadas de modo que a sensibilidade com relação ao outro (e sua proximidade - o próprio material da moralidade) é modificada radicalmente. Comportamentos que em outras épocas não eram objeto de interesse passam a ser considerados repugnantes, e proibições sociais são criadas como se novos tabus estivessem se institucionalizando, estabelecendo um novo limiar para os sentimentos de medo, repugnância e vergonha.

O mundo dos esportes é capaz de revelar de maneira mais direta a natureza moral desses novos tabus que se instituem. Como exemplo, podemos pensar na história do boxe, em que um aumento da sensibilidade e controle da violência se manifestou numa sucessão de modificaçōes das suas regras: na proibição do uso das pernas, no uso de luvas e seu posterior alcochoamento, na divisão dos lutadores por categoria e na delimitação do campo da luta. Ainda que permaneça nos esportes o ethos de imitação de batalha (Idem, p. 38), sua principal carac- terística, o que os diferencia das práticas antigas e medievais, é a tentativa de minimizar a violência. Assim, "a maioria dos esportes carregam um fator de competitividade. São competições que implicam o uso de força corporal ou habilidades não militares" (Idem, p. 35), mas o uso das regras se desenvolveu no sentido de minimizar a violência e reduzir a agressão física. Elias demonstrou que existe certo grau de afinidade entre a forma parlamentar e os jogos esportivos (Idem, p. 41).

A perspectiva histórica permite que tenhamos uma verdadeira compreensão da natureza e do grau de transformação ocorrida nos padrões de sensibilidade. Se pensarmos uma atividade desportiva que hoje consideramos violenta como, por exemplo, a luta livre, e a compararmos com as lutas tal como realizadas na antiguidade percebemos como se operou a mudança de sensibilidade captada pela ideia de civilização. Nas lutas de pancrácio da Grécia antiga, todo o corpo era usado (pés, cotovelos, joelhos, pescoço e cabeça), sendo que na versão espartana também se usava os dentes.

Os lutadores podiam arrancar os olhos uns dos outros [...] deslocar os dedos das mãos, os ossos dos braços e aplicar a chave de estrangulamento. Se um conseguia derrubar o outro, podia sentar-se em cima e golpeá-lo na cabeça, no rosto, nas orelhas, também podia dar-lhe chutes e pisoteá-lo [...]. Neste torneio brutal os lutadores recebiam às vezes feridas horríveis e muitas vezes acontecia de um ser morto (Mezoe apud Elias e Dunning, 1995, p. 169).

Nossa sensibilidade para formas violentas modificou-se de tal forma que, dificilmente, um espetáculo como esse poderia ser tolerado hoje. Mesmo a "luta livre" possui uma série de limitaçôes, como a proibição de golpes traumáticos, dedos nos olhos, beliscões, chave de rins, golpes nos olhos, nariz, boca e ouvido, puxôes de cabelo e mordidas. ${ }^{12}$ Tem-se ainda que considerar o fato de que as lutas acontecem num lugar e tempo delimitados, diante da presença de juízes que têm sua ação garantida e controlada por instituições. No caso específico do futebol, a sociologia figuracional demonstrou como a versão jogada hoje difere sobremaneira dos jogos 
com bola da Idade Média, onde, por exemplo, no “burling a campo aberto" o jogo era realizado no espaço entre duas ou mais localidades sem a limitação do número de jogadores entre os times, tampouco a sua diferenciação. A descrição seguinte pode dar uma boa ideia da mudança operada historicamente:

[...] Quando se reúnem, não se equipara o número de jogadores [...]: somente se lança uma bola de prata ao ar e a equipe que consegue agarrá-la e levá-la, por sua força ou perícia, até o lugar que foi demarcado, obtém a bola e a vitória. Quem quer que tenha a bola em seu poder se vê perseguido geralmente pelo grupo adversário; e este não lhe dará trégua até que (sem nenhum respeito) o portador seja derrubado na bendita terra de Deus [...] (Carew, 1602 apud Elias e Dunning, 1995, pp. 225-227).

Nessa descrição é possível entender por que durante tanto tempo os jogos coletivos foram considerados perigosos. Em 1302, o rei Eduardo II tentou banir os jogos com bola de Londres fazendo referência aos males despertados durante o jogo (Elias e Dunning, 1995). A bola chegou a ser muitas vezes considerada um objeto tomado por um espírito demoníaco pela fúria e paixão que suscitava sua disputa. Naquele mesmo relato antigo sobre o hurling, o cronista questiona o valor daquela prática:

[...] pois se por um lado proporciona força, resistência e agilidade a seus corpos e infunde valor aos seus corações para enfrentar o inimigo, também, por outro, está acompanhado de numerosos perigos. Alguns dos quais sempre atingem os jogadores [...]. Quando o hurling termina, vemo-los retirar-se para suas casas como se regressassem de uma dura batalha, com a cabeça aberta, ossos quebrados e deslocados, e com tais feridas que lhes fazem doentes por vários dias (Carew, 1602 apud Elias e Dunning, 1995, pp. 225-227).

Assim, em meio a essa transformação histórica na sensibilidade, é importante perceber que existe uma diferença fundamental entre a moral dos esportes na Grécia Antiga e na Inglaterra do século
XVIII. Na primeira, os jogos eram considerados um exercício ou preparação para a guerra. O significado da ação era sustentado pela demonstração das virtudes do guerreiro, e sua justeza não era fator predominante. Por sua vez, "a ética inglesa do fair play não tem raízes militares" (Elias e Dunning, 1995, p. 171). Este valor se desenvolveu na Inglaterra juntamente com uma mudança na natureza do prazer e da emoção, em que o esporte se tornou uma fonte de tensão-emoção agradável.

De fato, o desenvolvimento da ideia de fair play tem raiz em necessidades puramente instrumentais. A passagem a seguir é um resumo do argumento eliasiano que pode ser apresentado como uma crítica radical à perspectiva filosófica sobre o fair play:

O desfrute e a tensão emocional que o jogo proporcionava aumentaram de certo modo com o prazer das apostas, que na Inglaterra desempenharam um papel considerável na transformação das formas mais violentas de jogo em esportes e no desenvolvimento da ética do "jogo limpo". Os cavalheiros que presenciavam, como expectadores, algum encontro desportivo em que seus filhos, seus criados ou mesmo profissionais famosos jogavam, gostavam de apostar dinheiro em uma equipe ou em outra para sentir o "sabor" da emoção da própria competição, já temperada pelas restriçôes civilizadoras. Porém, a perspectiva de ganhar a aposta somente podia conferir emoção à luta se as probabilidades de ganhar estivessem repartidas mais ou menos equitativamente entre os dois lados e se podiam ser calculadas minimamente (Idem, pp. 171-172).

Assim, a partir do século XVIII, um código de normas que buscava limpeza e igualdade de oportunidades de ganhar se tornou mais rígido, com maior supervisão. Seu argumento é moral, contudo esse sentido de moralidade oculta a função e a necessidade de um ordenamento mais amplo da experiência. O fair play seria resultado da necessidade de apostadores e também do processo civilizador. Em suma, a sociologia figuracional explica as tensōes em torno do fair play como resultado de convençôes sociais desenvolvidas historicamente. No caso 
do time inglês Bolton apresentado anteriormente, todo o constrangimento causado no futebol inglês é explicado como resultado de uma tensão gerada entre o uso costumeiro e a inovação da regra, e não tem, necessariamente, uma natureza moral.

\section{Sociologia da moralidade}

O que dizer, então, do fair play? A busca por um "jogo limpo" seria um aspecto transcendental da experiência de jogar ou seu ideal de virtude estaria ocultando uma função de controle social? Que perspectiva explicaria melhor o fair play?

A discussão anterior mostrou que existe uma oposição fundamental entre a perspectiva filosófica e a da sociologia figuracional. Ainda que algumas das vertentes filosóficas possam ser adequadas a uma abordagem da situação de uso do fair play, outras (como, por exemplo, as que chamamos valorativas) estão em total oposição à história de sua prática tal como apresentada por Elias e Dunning. De fato, o que estes autores fazem é desqualificar completamente qualquer possibilidade de consideração do fair play como uma virtude ou valor universal, situando-o num momento muito específico da história (e com uma origem que seria a negação de toda substância da perspectiva valorativa). Devemos necessariamente assumir a postura da sociologia figuracional? Não existiria outro caminho para uma abordagem sociológica?

O objetivo deste trabalho é formular uma teoria sociológica do fair play, mas também, a partir desse esforço, revelar os dilemas da sociologia da moralidade. Tornou-se claro, a partir dos exemplos analisados, que a perspectiva sociológica eliasiana estabelece não só uma crítica como também a própria desqualificação da vertente valorativa do fair play. Para a sociologia figuracional, o tipo de explicação filosófica seria uma ausência de conhecimento ou falta de dados históricos sobre o fato em questão. Esse argumento poderia também ser ampliado e aplicado a todas as experiências e discursos da moralidade: recorrer à moralidade como explicação significa desconhecimento de mecanismos sociais. Dessa maneira, o conhecimento sociológico da moralidade tornar-se-ia uma versão de relativis- mo radical. Por isso, podemos denominar esta perspectiva sociológica da moralidade de positiva. A ideia aqui não é escolher entre uma perspectiva positiva ou transcendental, mas demonstrar que uma sociologia da moralidade crítica precisa ser construída pelo confronto entre as duas perspectivas e, especialmente, a partir de uma reconsideração do lugar dos valores transcendentais.

Há dois argumentos fundamentais contra a perspectiva positiva. $\mathrm{O}$ primeiro diz respeito ao sentido da experiência dos atores. Ainda que o fair play tenha sua origem no interesse de apostadores na Inglaterra do século XVIII, isso não significa que seu sentido hoje seja necessariamente devedor daquela situação. O fato é que tanto no nível epistemológico como em termos da significação da experiência dos atores, o sentido do fair play não está necessariamente determinado pela sua origem histórica.

Ainda de um ponto de vista epistemológico, também não é possível determinar se o sentido da virtude que animava os jogos da Antiguidade se perdeu completamente. O problema está no fato de que, apesar das origens apontadas por Elias, o uso do fair play pelos atores sociais tem um significado no momento da experiência que se refere ao sentido das virtudes. Quando os jogadores discutem e optam pelo estabelecimento do fair play, o que eles buscam com suas ações? Caso a ideia de "jogo limpo" tenha surgido mesmo da necessidade de apostadores, podemos argumentar que, nos exemplos citados, o significado buscado pelos atores na hora do jogo traiu essa origem (postura transcendental fraca) ou mesmo que a necessidade dos apostadores traiu o sentido do fair play (postura transcendental forte).

Em suma, do ponto de vista da experiência e do seu significado para os atores, o uso do fair play remete a um valor transcendental. Não estamos afirmando que seja transcendental, e sim que remete a um valor transcendental. Caso perguntemos se é válido ganhar a Copa do Mundo com um gol feito por "la mano de Dios" ou se perguntamos se o jogador deve agir como Edmundo ou Rivaldo, as respostas necessariamente têm uma pretensão transcendental que julga a experiência e a vida. Não estamos diante de uma arrogância dos torcedores que, sem os meios, querem ter opiniōes. Estamos, sim, diante da natu- 
reza da moralidade, em que o ator é capaz de argumentar e, ao falar sobre a vida, não consegue escapar das pretensões transcendentais.

O segundo argumento contra a perspectiva positiva diz respeito ao lugar da crítica. Aqui seguimos a perspectiva de uma sociologia da moral baseada no pensamento de Theodor Adorno (2000, 2008). Caso sejam eliminados da sociologia da moral toda referência a valores transcendentais, recai-se em um relativismo radical em que a própria natureza da moralidade é desnaturada: moralidade torna-se cultura. $\mathrm{O}$ problema desta transformação não está só no fato de que significados da experiência são deixados de lado, mas, especialmente, na impossibilidade da crítica. Não havendo qualquer referência transcendental no entendimento da composição normativa da vida social, estaríamos diante de uma aceitação da "vida falsa", e a sociologia não pode fazer mais do que compor seu retrato. Deve ficar claro que não se trata de requerer que a sociologia possa integrar ao seu corpo teórico o problema do transcendental, contudo é importante perceber a existência de uma dimensão da experiência social (sentimentos morais) que precisa ser mais bem entendida no seio da disciplina, não apenas com o intuito de descrever essa experiência específica, mas também para que se tenha uma consideração dos valores que orientam a própria crítica.

Do ponto de vista sociológico existe um modelo teórico de equalização entre regras do jogo, sociais e morais, que as interpreta e as transforma em regras de coerção. Contudo, o apego dos indivíduos às regras morais possui caráter mais amplo do que a internalização do medo ou constrangimento e, portanto, não pode ser entendido simplesmente como uma relação com as convenções socialmente aceitas. O sentido que anima a revolta contra o "gol de mão" ou a admiração diante de demonstrações de fair play é, do ponto de vista da filosofia moral, completamente distinto de outras convençôes sociais. Mas, mesmo que a sociologia não possa incorporar completamente essa dimensão sob pena de contradizer seu próprio fundamento como ciência, é necessário reconhecer a diferença desses sentidos para a experiência dos atores.

O problema principal está na forma como a ideia de uma dimensão transcendental pode ser dis- cutida dentro da sociologia (que nasceu como crítica e suspeita de todas as formas transcendentais). Por isso, a discussão do fair play pode ter um efeito esclarecedor se afirmarmos que este seria um exemplo do tipo de forma semitranscendental buscada pelo pensamento negativo (Adorno, 2000).

Não é possível realizar uma opção racional entre a interpretação transcendental e positiva do fair play. $\mathrm{O}$ argumento positivo é, de fato, uma importante refutação da ideia de uma virtude universal ao apresentar não só o seu caráter disputável (o debate entre os jogadores, a dúvida entre os torcedores) como também sua constante perversão (necessidade da aposta, doping). Contudo, essa perspectiva não consegue explicar como culturas e linguagens distintas são capazes de entender e requerer o mesmo valor, nem tampouco o porquê da possibilidade de uma comparação trans-histórica.

Todavia, esses problemas reforçam a noção de uma perspectiva semitranscendental se pensarmos que estamos tratando não de um valor universal, mas de um valor universalizável. Assim, um valor como "jogo limpo" não é universal, porém se universalizou no desenvolvimento histórico. O reconhecimento da virtude do fair play não é imanente aos jogos; o que é imanente é a necessidade de justiça ou de fundamentação da normatividade. Essa necessidade origina o ato de recorrer a um valor específico (no caso, o fair play) que se universaliza por meio de formas sociais e históricas, como negociação, educação e até violência.

Uma teoria sociológica do fair play não será capaz de, nem deverá, estabelecer um julgamento do seu valor intrínseco. Contudo, precisa reconhecer, e isso é válido para toda a sociologia da moralidade que se pretenda também uma crítica, que seu uso e significado só podem ser entendidos caso se considere sua natureza semitranscendental.

\section{Conclusão}

Este artigo procurou demonstrar as dificuldades envolvidas numa teorização sociológica do fair play. Os casos empíricos apresentados demonstraram que o fair play envolve mais que o cumprimento das regras; em todos eles percebemos a 
recorrência a um sentido para orientar e organizar as ações dos jogadores que não era, do ponto de vista do que é estabelecido pelas regras, necessário. Nossa discussão problematizou como esse sentido é interpretado por algumas perspectivas filosóficas e pela sociologia figuracional. As interpretaçôes seguem caminhos divergentes ao relacionar a necessidade do fair play com (1) um sentido que se dá no momento do jogo, como parte da moralidade no encontro do outro, ou com (2) o desenvolvimento e a consolidação de valores derivados do contexto histórico inglês. Não era nossa intenção escolher ou eliminar qualquer uma das interpretaçôes, mas demonstrar os problemas da abordagem figuracional e derivar disto algumas críticas a uma perspectiva sociológica positiva da experiência moral. Assim, a tentativa de compreensão do fair play e sua universalidade/universalização exemplifica o tipo de problema envolvido na construção de uma sociologia crítica da moralidade, qual seja, a relação com formas transcendentais. Partindo de uma perspectiva adorniana, propomos a noção de algo semitranscendental como fundamento para a sociologia da moralidade. Tal noção ajuda na compreensão do fair play, uma vez que leva em consideração sua origem histórica e seus diferentes usos, mas não abdica do sentido compartilhado na experiência dos jogadores e das razões de sua expansão como valor fundamental para as mais diferentes práticas.

Por fim, é importante ressaltar que nosso argumento não tratou detalhadamente do problema da "esportivização". O contexto dos esportes de alta performance traz uma série de problemas para a compreensão do fair play que não pudemos abordar aqui. Diferentemente dos jogos de improviso, quando jogar está intrinsecamente relacionado com o exercício de virtudes, os esportes de alta performance substituem a expectativa de valores ou virtudes por uma série de formas de controle institucionalizadas. Além disso, interesses externos assumem papel importante na experiência do jogo. Acreditamos que, do ponto de vista de uma sociologia da moralidade, os esportes de alta performance não podem ser simplesmente encarados como negação do fair play, mas que, com base na abordagem aqui proposta, podemos compreender essas tensões como a própria experiência da moralidade.

\section{Notas}

1 Disponível em <http://www.fifa.com/aboutfifa/worldwideprograms/footballforhope/fairplay/code.html>.

2 O quarto princípio do Código de fair play da Fifa estabelece de modo muito claro o respeito pelas regras como fundamental e relaciona-o com uma espécie de bom comportamento: "Respeite os adversários, os companheiros de time, os árbitros, representantes $\mathrm{e}$ os expectadores. Fair play significa respeito. Respeito é parte do nosso jogo. Sem adversários não pode haver jogo. Todos tem o mesmo direito, inclusive o direito de ser respeitado. Os companheiros de time são colegas. Formam um time em que todos os membros são iguais. Os árbitros estão lá para manter a disciplina e o Fair Play. Aceite sempre as decisões deles sem discutir e ajude-os a fazer com que todos os participantes tenham um jogo agradável. Os representantes também fazem parte do jogo e devem, dessa forma, ser respeitados. Os expectadores dão ao jogo a sua atmosfera. Eles querem ver o jogo sendo jogado de forma justa, mas devem se comportar de forma justa e respeitarem a si próprios". Disponível em <http://www.fifa.com/ aboutfifa/worldwideprograms/footballforhope/fairplay/code.html>, acessado em 20.8.2009.

3 Disponível em < (http://cbfnews.uol.com.br>.

4 Chamamos de "decisão infraconstitucional" aquela tomada nas reuniões ordinárias anuais do International Football Association Board para esclarecimento, ou mesmo mudanças sutis, de qualquer uma das 17 regras do futebol. Por exemplo, o impedimento passivo está definido em uma decisão deste tipo e não no enunciado da própria regra.

5 Disponível em <www.uefa.com/news/newsid=145533, printer.htmx>, acessado em 16.8.2007.

6 Disponível em <www.news.bbc.co.uk>, acessado em 20.10.2008.

7 Disponível em <www.carosi.freeserver.co.uk/corshamreferee/offside.htm >.

8 O jogo ocorreu no dia 20 de setembro de 2005, o Ajax de Amsterdam jogou com o Cambuur Leeuwarden disputando a Gatorade Cup, a Taça da Holanda.

9 Para um vídeo do lance, ver <http://www.youtube. $\mathrm{com} /$ watch?v=yhib5GKBP14>.

10 É interessante pensar, por exemplo, o caso do Ajax e Cambuur Leeuwarden ocorrendo entre o Sport Recife e o Santa Cruz em Pernambuco; as reações dos torcedores certamente fariam referência a todo o espectro de posturas e sentimentos morais. 
11 É importante notar que o "vale tudo" que qualifica uma modalidade de luta se refere ao estilo de arte marcial a ser empregado por cada lutador e não as suas ações.

12 Cf. em <http://lutalivresubmission.com.br/?fx=pagin al>, acessado em 18.9.2009.

\section{BIBLIOGRAFIA}

ADORNO, Theodor W. (2000), Problems of moral philosophy. Cambridge, Polity Press. . (2001), Metaphysics: concepts and problems. Cambridge, Polity Press. . (2006), History and freedom. Cambridge, Polity Press. . (2007), Introdução à sociologia. São Paulo, Editora da Unesp. . (2008), Minima moralia: reflexóes a partir da vida lesada. Rio de Janeiro, Azougue. ALEXANDER, Jeffrey. (2001), "Towards a sociology of evil: getting beyond modernist common sense about the alternative to 'the good'", in M. P. Lara (org.), Rethinking evil: contemporary perspectives, Los Angeles/Berkeley, University of California Press, pp. 153-172.

BOLTANSKI, Luc \& THÉVENOT, Laurent. (2006), On justification: economies of worth. Princeton, Princeton University Press.

D’AGOSTINO, Fred. (1981), "The ethos of games". Journal of the Philosophy of Sport, 8 (1): $7-18$.

DUNNING, Eric. (1996), "On problems of the emotions in sport and leisure: critical and counter-critical comments on the conventional and figurational sociologies of sport and leisure”. Leisure Studies, 15 (3): 185-207.

(1997), "Sport in the quest for excitement: Norbert Elias's contributions to the sociology of sport”. Group Analysis, 30 (4): 477-487.

(2003), El fenómeno deportivo: estudios sociológicos en torno al deporte, la violencia y la civilización. Barcelona, Editorial Paidotribo.

(2004), "Sociology of sport in the balance: critical reflections on some recent and more enduring trends". Sport in Society, 7 (1): 1-24.
DURKHEIM, Émile. (1953), Sociology and philosophy. Londres, Cohen \& West.

ELIAS, Norbert. (1993), O processo civilizador: formação do estado e civilização. Rio de Janeiro, Jorge Zahar.

. (1994a), O processo civilizador: uma história dos costumes. Rio de Janeiro, Jorge Zahar.

. (1994b), A sociedade dos individuos.

Rio de Janeiro, Jorge Zahar.

(1998), Envolvimento e alienação. Rio de Janeiro, Bertrand Brasil.

. (1998), The Norbert Elias reader: a biographical selection. Oxford, Blackwell.

. (2005), Introdução à sociologia. Lisboa, Edições 70.

. (2006a), "Figuração", in

Escritos \& ensaios 1: Estado, processo, opinião pública, Rio de Janeiro, Jorge Zahar.

. (2006b), "Tecnização e civilização", in Escritos e ensaios 1: Estado, processo, opinião pública, Rio de Janeiro, Jorge Zahar. ELIAS, Norbert \& DUNNING, Eric. (1966), "Dynamics of group sports with special reference to football". British Journal of Sociology, 17 (4): 388-402.

(1995). Deporte y ocio en el proceso de la civilización. Trad. de Purificación Jiménez. 2 ed. México, Fondo de Cultura Económica.

ELIAS, Norbert \& SCOTSON, John. (2000), Os estabelecidos e outsiders: sociologia das relaçôes de poder a partir de uma pequena comunidade. Rio de Janeiro, Jorge Zahar.

GIULIANOTTI, Richard. (2002), Sociologia do futebol: dimensóes históricas e socioculturais do esporte das multidões. Trad. Wanda N.C. Brant e Marcelo de O. Nunes. São Paulo, Nova Alexandria.

GOODGER, J. M. \& GOODGER, B. C. (1989), "Excitement and representation: toward a sociological explanation of the significance of sport in modern society". Quest, 41 (3): 257-272.

KALLSCHEUER Otto. (1995), "'And who is my neighbor?': moral sentiments, proximity, humanity”. Social Research, 62 (1): 99-127.

KEW, Francis. (1992), "Game-rules and social theory". International Review for the Sociology of Sport, 27 (4): 293-307. 
KORSGAARD, Christine M. (1996), The sources of normativity. Nova York, Cambridge University Press.

MacINTYRE, Alasdair. (2001). Depois da virtude. Bauru, Edusc.

MAGUIRE, Joe. (1986), "The emergence of football spectating as a social problem 1880-1985: a figurational and developmental perspective". Sociology of Sport Journal, 3 (3): 217-244.

MANGAN, J. A. (1986), The games ethic and imperialism: aspects of the diffusion of an ideal. Harmondsworth, Viking.

MORAIS, Jorge Ventura de \& BARRETO, Túlio Velho. (2008), "As regras do futebol e o uso de tecnologias de monitoramento". Estudos de Sociologia, 14 (2): 129-156. . (2009), "Las reglas del fuera de juego y la dinámica del fútbol: un análisis a partir de la sociología figuracional", in C. V. Kaplan e V. Orce (orgs.), Poder, prácticas sociales y proceso civilizador: los usos de Norbert Elias, Buenos Aires/México, Noveduc, pp. 191-199.

MURRAY, Bill. (2000), Uma história do futebol. Trad. Carlos Szlak. São Paulo, Hedra.

SHEARD, Kenneth G. (1997), "Aspects of boxing in the western 'civilizing process". International Review for the Sociology of Sport, 32 (1): 31-57.

SHERIDAN, Heather. (2003), “Conceptualizing 'fair play': a review of the literature". European Physical Education Review, 9 (2): 163-184.

SMART, Barry. (2003), "Sociology, morality and ethics: on being with others", in G. Ritzer \& B. Smart (orgs.), Handbook of social theory. Londres, Sage, pp. 509-519.

TESTER, Keith. (1994), Media, culture, and morality. Londres/Nova York, Routledge. . (1997), Moral culture. Londres/Thousand Oaks, Sage.

TOLEDO, Luiz Henrique de. (2002), Lógicas no futebol. São Paulo, Hucitec/Fapesp. . (2008), "Jogo livre: analogias em torno das 17 regras do futebol”. Horizontes Antropológicos, 30: 191-219.

TORRES, C. \& CAMPOS, D. (orgs.). (2006), La pelota no dobla? Ensayos filosóficos en torno al fútbol. Buenos Ayres, Libros de Zorzal. 


\section{REGRAS DE JOGO VERSUS REGRAS MORAIS: PARA UMA TEORIA SOCIOLÓGICA DO FAIR PLAY}

Simone Magalhães Brito, Jorge Ventura de Morais e Túlio Velho Barreto

Palavras-chave: Moralidade; fair play; teoria crítica; sociologia figuracional; Jogo.

O objetivo deste trabalho é apresentar e discutir as dificuldades presentes na tentativa de construir uma explicação sociológica da ideia de fair play, sobretudo nos esportes. Como é possível que esportes tão diferentes em termos de suas regras de contato corporal possam fazer uso do mesmo princípio para resolver problemas não determinados em suas regras específicas? Figurações sociais tão distintas quanto as estabelecidas no badminton ou no boxe, nas situações oficiais ou nas "brincadeiras", também requerem a mesma virtude. Qual seria, pois, a explicação sociológica para a universalidade do fair play? Neste trabalho, procuramos demonstrar como a resposta a essas questōes requer um debate dos fundamentos da teoria sociológica e aponta igualmente para a necessidade de se desenvolver os fundamentos de uma sociologia da moralidade.

\section{GAME RULES VERSUS MORAL RULES: TOWARDS A SOCIOLOGICAL THEORY OF FAIR PLAY}

Simone Magalhães Brito, Jorge Ventura de Morais, and Túlio Velho Barreto

Keywords: Morality; fair play; critical theory; figurational sociology; Game.

The objective of this work is to present and discuss the difficulties involved in the attempt to construct a sociological explanation of the idea of fair play - especially in sports. How is it possible that sports such as rugby and football, so different in terms of their rule for bodily contact, can draw upon the same principle to resolve problems not covered in their own rules? Social figurations as distinct as those established in badminton or in boxing, either in official or nonofficial situations, also require the same virtue. In sum, what is the sociological explanation for the universality of fair play? In this work we try to show how an answer to these questions requires a debate on the foundations of the sociological theory and equally points to the necessity to develop the foundations of a sociology of morality.

\section{RÈGLES DU JEU VERSUS RÈGLES MORALES: VERS UNE THÉORIE SOCIOLOGIQUE DU FAIR PLAY}

\section{Simone Magalhães Brito, Jorge Ventura de Morais et Túlio Velho Barreto}

Mots-clés: Moralité; Fair play; Théorie critique; Sociologie figurationnelle; Jeux.

L'objectif de ce travail est de présenter et de discuter les difficultés existantes dans la tentative de construire une explication sociologique à l'idée de fair play, surtout dans les sports. Comment est-il possible que des sports aussi différents quant aux règles de contact corporel puissent faire usage du même principe pour résoudre des problèmes qui ne sont pas déterminés par ses règles spécifiques? Des figurations sociales aussi distinctes que celles établies dans le badminton ou dans la boxe, dans les situations officielles ou dans les "jeux", requièrent également la même vertu. Quelle serait, alors, l'explication sociologique pour l'universalité du fair play ? Dans ce travail nous avons tenté de démontrer de quelle façon la réponse à ces questions requiert un debat sur les fondements de la théorie sociologique et indique le besoin de développement des fondements d'une sociologie de la moralité. 